Europe's Journal of Psychology 1/2010, pp. 44-62

www.ejop.org

\title{
Developmental dyslexics and unimpaired children's reading and memory for words in a transparent orthography
}

\author{
Natasza Dominika Nalesnik \\ Institute of Psychiatry University of London
}

Bahman Baluch

Middlesex University

\begin{abstract}
Word reading and short-term memory performance of forty two developmental dyslexics (mean age 10.1 years, SD $=.7$ ) and thirty three unimpaired reading age matched (mean age of $8.5, S D=.5$ ) and thirty six unimpaired chronological age matched children (mean age of $10.6, \mathrm{SD}=.7$ ) was investigated in transparent Polish orthography. Fifty of the children were instructed that they were expected to recall the list of (12 high frequency mainly concrete) words after reading them aloud (Condition A), whilst others had no such instructions (Condition B). Word reading was tested by recording the time taken to read aloud the list of words in seconds and by taking into account errors in pronunciation. Overall, word reading was significantly slower for developmental dyslexics compared to reading age (RA) and chronological age (CA) controls. However, developmental dyslexics' recall of words was comparable to CA and significantly superior to RA both in conditions $A$ and $B$ of the experiment. The implications of these results in relation to the impact of spelling transparency on memory performance of impaired and unimpaired readers are discussed.
\end{abstract}

Keywords: spelling transparency; Polish; developmental dyslexia; word reading; memory

\section{Background}

There has been considerable research examining the significance of phonological processing in the development of reading and spelling (e.g., Ehri, 1999; Frith, 1980) developmental dyslexia (e.g., Goswami \& Bryant, 1990; Snowling, 1980; Swan \& Goswami, 1997) and memory processes (e.g., Baddeley, 1986; Baddeley, 1990). More recently however, there is a growing interest in examining the extent to which 
the manner in which a particular orthography represents phonology of the spoken language has its unique effect on the development of reading and spelling (Rack, Hulme, Snowling \& Wightman, 1994), developmental dyslexia (Goulandris, 2003) and memory processes (Baluch \& Danaye-Tousie, 2006a). The aim of the present study is to examine word reading and short-term recall of words in Polish which insofar as grapheme-phoneme conversions are concerned has a transparent orthography (Reid, 2005). Grapheme phoneme conversion is a process by which the reader transforms words graphemes (letters) to the corresponding phonemes (sounds) using linguistic rules of the language. The outcome should be arrival at the word's correct pronunciation. There has been little systematic research on the development of reading and spelling in Polish, and none has been reported on short-term memory for dyslexics and unimpaired readers.

Phonological processing and development of reading

The role of phonology as a mediating factor in children's development of reading has found considerable support in the developmental literature (e.g., Rack, Hulme, Snowling \& Wightman, 1994; Sprenger-Charolles, Siegel, Béchennec \& Serniclaes, 2003). According to the most influential developmental models (Ehri, 1999; Ehri \& Snowling, 2004; Frith 1980) reading and spelling develops through distinct stages from logographic (or pre-alphabetic) to alphabetic, leading to the establishment of an orthographic lexicon. In this respect the alphabetic phase is seen as an important stepping stone in transition to the orthographic stage. This is the stage in which beginner readers learn the connections between letters (graphemes) and corresponding phonemes and use the grapheme-phoneme correspondence as a process in word reading/recognition (Ehri, 1999). Further support of the role that phonological processing may play in the development of reading comes from studies on phonological awareness tasks, the ability to manipulate and show an understanding of any phonological unit within a word, be it phoneme, rime, or syllable (Adams, 1990; Brady \& Shankweiler, 1991; Goswami \& Bryant, 1990; Wagner \& Torgesen, 1987). Research has generally shown that children, who show good performance on such tasks both at pre and post literacy level, demonstrate greater reading skills than those who show poorer performance. A further test of the role of phonological processing in reading has been on reading performance of children classed as developmental dyslexics (Goswami \& Bryant, 1990; Snowling, 1980; Swan \& Goswami, 1997). Dyslexic children are slower and make more errors compared to unimpaired readers in reading words and non-words aloud (Jackson \& Coltheart, 2001 ) and show greater difficulty in tasks involving phonological awareness (Brady \& Shankweiler, 1991; Goswami \& Bryant, 1990; Wagner \& Torgesen, 1987). The general consensus is that perhaps these differences demonstrate difficulties in phonological 
processing and/or problems associated with transition at the alphabetic stage of reading (e.g., Frith, 1980).

Orthographic transparency and development of reading

There is now a growing body of research examining the impact of orthographic transparency on the development of reading (see Goulandris, 2003). Orthographies differ in the extent to which phonological information may be extracted from the print via grapheme-to-phoneme conversions (see Frost, Katz \& Bentin, 1987). It has been argued that in the case of scripts like Serbo-Croatian, in principle a simple grapheme-to-phoneme conversion without lexical involvement should enable correct generation of a word's pronunciation. English spelling represents a position somewhere in the middle of transparency-opaqueness continuum. This is because of the presence of words with irregular spellings (Frost et al., 1987). According to Coltheart's (1978) influential dual route model and the more recent cascade model (Coltheart, Cutris, Atkins \& Haller, 1993) English words that conform to spelling sound rules may be read via grapheme-phoneme conversions and those that are exceptions to the rules (irregular) are read via the direct lexical route. It has been suggested that beginner readers of English may find it particularly difficult to encode exception words using the grapheme-phoneme strategy and may rely on alternative lexical strategy for recognition of exception words (Barron 1986). At the far extreme of opaqueness, however, there are scripts such as vowel free Hebrew in which there is a greater need for a direct lexical route in generation of a correct pronunciation because pointers representing the vowels /a, e, i, o/ and /u/ are usually omitted. In view of differences between orthographies with regard to transparency it has been argued that if the development of reading relies on efficiency of phonological generation from print, it would be easier to read in a transparent orthography as this may facilitate recognition of words using graphemephoneme conversions. If so, there may be a lower prevalence rate of reading impairment for transparent writing systems (De Gelder \& Vroomen, 1991; Nikolopoulos \& Goulandris, 2000; Snowling, 2004).

Cross-language comparisons have shown that children reading transparent orthographies such as Greek (Porpodas, Pantelis, \& Hantziou, 1990) and Italian (Cossu, Gugliotta, \& Marshall, 1995) perform more accurately in reading words and non-words compared to children reading in English (Frith, Wimmer, \& Landerl, 1998). Moreover, bilingual English and Hebrew beginner readers were found to read more accurately when Hebrew is vowelized than unvowelized, or when reading regular compared to irregular English words (Geva \& Siegel, 2000). There is also evidence that both spelling and word recognition in terms of oral reading is easier in 
transparent orthographies such as Turkish than in deep orthographies such as English (Oney, Peter, \& Katz, 1997; Raman, Baluch \& Sneddon, 1996).

Baluch and Danaye Tousie (2006a) examined the impact of transparency of a word spelling on reading in Persian which is transcribed by two kinds of spellings namely; words spelled with vowels (letters) transcribed as a fixed part of the spelling (transparent) and words spelled with vowels (diacritics) omitted (opaque). The results showed that dyslexic Persian children perform worse (slower reading and more errors) compared to both unimpaired reading and chronological age controls. According to Castles and Coltheart (1993) and Manis, Seidenberg, Doi, McBrideChang and Peterson (1996), more specific information regarding reading behaviour of dyslexic readers may be gained by providing two groups of unimpaired "controls" in the study. Comparison of reading performance of developmental dyslexics with unimpaired readers of the same age (CA) may show how delayed a reader may be in reaching a normal phase of reading. However, the comparison of developmental dyslexics with unimpaired readers of the same reading age (RA) may demonstrate the extent of deviance from patterns of reading which do not correspond to any of the normal reading stages. The findings from Persian thus suggest that dyslexics have indeed greater difficulty with phonological processing compared to RA controls and the effect is true even for transparent words. Furthermore, it is important to note that Baluch and Danaye-Tousie's study had used mainly high frequency words in their experiment. Thus the finding that even with high frequency words there is slower reading and more errors for dyslexics is of interest particularly in relation to the impact of spelling transparency and the development of reading. The findings from Persian, however, are not surprising and have also been reported in relation to reading English, which like Persian has a mixture of regular (transparent) and exception (opaque) spellings (e.g., Olson, Wise, Conners, Rack, \& Fulker, 1989). The question is whether a similar pattern may also be observed in an orthography like Polish in which the relationship between graphemes and phonemes are entirely consistent? Alternatively, one may argue that perhaps the latter significant deficits in phonological processing is evident only in scripts like Persian and English with mixture of opaque and transparent spellings. The little reported research on reading in transparent orthographies other than Polish is not entirely conclusive. For example, evidence from regular Dutch suggests that dyslexic children perform similar to their reading-age controls but worse than their chronological-age controls on reading tasks (Messbaver \& de Jong, 2004). However, in Hindi which is also a transparent orthography, Gupta (2004) reported that dyslexics were worse in reading accuracy compared to both RA and CA controls. 
Phonological processing and working memory

Phonological processing is also argued to play an important role in working memory (Baddeley, 1990; Just \& Carpenter, 1992). Working memory is argued to comprise of a central executive which functions as a control mechanism, and two temporary storage systems: verbal and visuo-spatial. The verbal sub-system plays a particularly important role in temporary storage of phonologically coded information. The efficient functioning of the system in relation to reading and comprehension is argued to depend on fast and error free retrieval of phonological information generated from print (Baddeley, 1990; de Jong, 1998; Just \& Carpenter, 1992). Children classed as poor readers or dyslexic may have particular problems with memory processing for at least two reasons: a) difficulties in encoding words due to poor grapheme-phoneme processes when reading words and b) difficulties due to the taxing of the limited capacity attention system due to a slower processing strategy (attention demanding). Hence there is growing evidence that dyslexics show poor performance on general verbal span tasks as well as tasks requiring visual spatial processing (Smith-Spark \& Fisk, 2007).

\section{Orthographic transparency and working memory}

There has been little research on orthographic transparency and working memory. Baluch and Danaye Tousie were amongst the first to examine this subject amongst both adults (Baluch \& Danaye-Tousie, 2006b) and children (Baluch \& Danaye-Tousie, 2006a). In relation to data on children, it was found that contrary to word reading performance dyslexics recall of words, in particular transparent words, was comparable to CA control and significantly better than RA control. Similar results were also reported by Swanson (1993) in which dyslexic children performed better on memory tasks compared to their reading age controls. According to Baluch and Danaye-Tousie (2006a) the following could account for the above pattern of results: Firstly, it could be the case that the words used in the study are mainly high frequency and dyslexics may rely on a more superior orthographic memory to compensate for their poorer phonological skills (Funnell \& Davison, 1989). McDougall and Donohoe (2002) also reported that the difference in short-term memory is minimal with high frequency words for poor and good readers but greater with low frequency words. A second explanation could be in view of the maturity of dyslexics who are 2 years older than RA control. It is possible that dyslexics take more "strategic" advantage of instructions to recall words after naming aloud hence their better performance. Rack et al., (1992) also argued that dyslexic readers who are older than the reading age matched control may have additional skills and strategies to bring to bear on reading tasks. In this respect, the additional skills by 
more mature dyslexic readers may have been more useful when dealing with transparent words that are less taxing at the grapheme-to-phoneme conversions.

\section{Research questions}

The first aim of the present study is to compare reading performance of developmental dyslexics in Polish with unimpaired reading age (RA) and chronological age (CA) controls. The materials to be used for reading will be high frequency and mainly concrete words (comparable to the study by Baluch and Danaye Tousie 2006a) study). Furthermore, the age of participants will be as close as possible to the latter study. If developmental dyslexics in Polish show greater difficulty in reading compared to both RA and CA, this further supports a view in which both in Persian and in transparent Polish there are significant deficits due to phonological processing as a result of being dyslexic. If, however, developmental dyslexics perform comparable to the reading-age controls but worse than the chronologicalage controls, this may suggest that perhaps reading in an entirely transparent orthography is a factor affecting the magnitude of differences between groups.

A second aim of the present study is to examine recall of mainly high frequency words in Polish by dyslexics, RA and CA controls with regard to high frequency words and under two experimental conditions. Condition $A$ in which readers are explicitly told that they are expected to recall words and condition $B$ in which there are no such instructions. If in an entirely transparent Polish orthography dyslexics show a similar pattern to that of Persian dyslexics; this is further confirmation that insofar as high frequency words are concerned dyslexics do not show a memory deficit for such words. However, equally important interest is in relation to presence and absence of instruction about recall of words. If dyslexics are strategically better able to take advantage of prior instructions to recall words one would expect a significant group by condition interaction.

\section{Polish Orthography}

Polish is an inflectional orthography, which belongs to the Western group of North Slavic languages, other members of this language group are the Slovak and Czech (Reid, 2005). Polish is written in the Roman script tailored to the phonological system of language by combining letters into digraphs. The alphabet consists of 35 letters in which 23 of these letters are considered as basic letters, nine with diacritics and three that only occur in foreign borrowings (Reid, 2005). A feature of the Polish orthography is its high consistency of letter-sound correspondence, but rather low sound-letter mapping. Therefore, whereas reading should not present problems, 
spelling may do. These features of the Polish orthography resemble that of German and Portuguese languages (Reid, 2005). Schooling is based on a phonic approach i.e., the introduction of letter sound correspondence in consonants and vowels, e.g., 'c' like 'cat' ( 'k' like in 'kot'). At a later stage word analysis and blending skills are being introduced with diacritics and digraphs being introduced last. Also reading syllable by syllable is encouraged as an intermediate step to whole-word recognition. Children are expected to be able to read the whole alphabet in conjunction with words and to be competent in reading by the end of the first schooling year (Brzezińska \& Ziółkowska, 1987).

Methods

Participants

A total of 111 Polish children took part in the present study. Forty two of the children (28 male and 14 female) mean age 10.1 years (SD $=.7$ ) were classed as developmental dyslexic. The process of being diagnosed as developmental dyslexic in Poland is that children are being referred by the School Pedagogues to a Pedagogical clinic were they are being required to attend a special psychological clinic for a two day assessment using reading, maths, motor skills and IQ test (Raven's Coloured Matrices Test, Raven, Court, \& Raven, 1977). The prevalence of dyslexia is reported to be $9-10 \%$ of children (Bogdanowicz, 2006). According to information from the School Pedagogies to the first author dyslexic participants were selected for the present study who were matched with unimpaired controls (see below) on parents education and economic status and there was no difference in their IQ (all children taking part in the present study scored about or above 75 percentile). None of the dyslexic or unimpaired children showed any emotional or neurological problems. Thirty three children (17 male and 16 female) were matched on reading age (RA) according to the information provided by their teachers with mean age 8.5 years $(S D=.5)$. Thirty six children $(20$ male and 16 female $)$ made up the chronological age (CA) control with mean age of 10.6 years (SD $=.7$ ).

Materials

Seven 'initial education' teachers were asked to come up with a list of thirty two one syllable, mainly concrete words, which came up frequently in grades 1 and 2 Polish textbooks. Of which twenty four were randomly chosen for the present study. None of the words had any apparent inter-semantic relationship. Half of the words were used in the practice trial and another half in the actual experiment. All words were 
printed in 16 font size, 12 each on an A4 card (see Appendix for the words used in the experiment).

Procedure

The study was conducted in four primary schools in Cracov and Rzeszow. Approval to conduct the study on school premises was obtained from the Head teacher and the whole procedure was overlooked by the School Pedagogue. All parents gave written consent for their children to participate in the study.

Participants were assigned to either of two conditions: In condition A both for practice and the experimental trial children were asked to read the list of words as 'quickly as possible' and were informed beforehand that they would be required to recall as many words as possible in a follow up test. In condition B children were only informed to read the list of 12 words as quickly as possible and no mention was made at this stage about recall of words. In both conditions reading the words was followed by a distracter task of making a simple addition of a 2 by 2 digit figure for no longer than 20 seconds. This was immediately followed by recalling as many words as possible in 60 seconds. The reason for using a distracter task is that it has been shown that recent words on a list of words are better recalled in short-term memory test in view of different strategies adopted by the participants (Baddeley \& Hitch, 1993). Thus by using a distracter task, which was also employed in Baluch \& Danaye-Tousie's (2006a) study, it is hoped that the recency effect is minimized. Each participant was tested individually and the session lasted no longer than 15 minutes. A tape recorder was used to record the session and for detecting errors of reading aloud at a later stage. A stop watch was used to measure the time taken for reading aloud. Errors in reading were predominantly mispronunciations.

Results

The mean time taken to read the list of words (in seconds), the number of errors in reading, and the number of correctly recalled words with their corresponding standard deviations (SD) are represented in table 1. Table 2 represents the inter correlations between the main variables in the present study, namely number of words recalled, age of participants, time taken to read the words and number of errors. 
Table 1: Mean, Standard Deviations for Each Measure and Experimental Condition

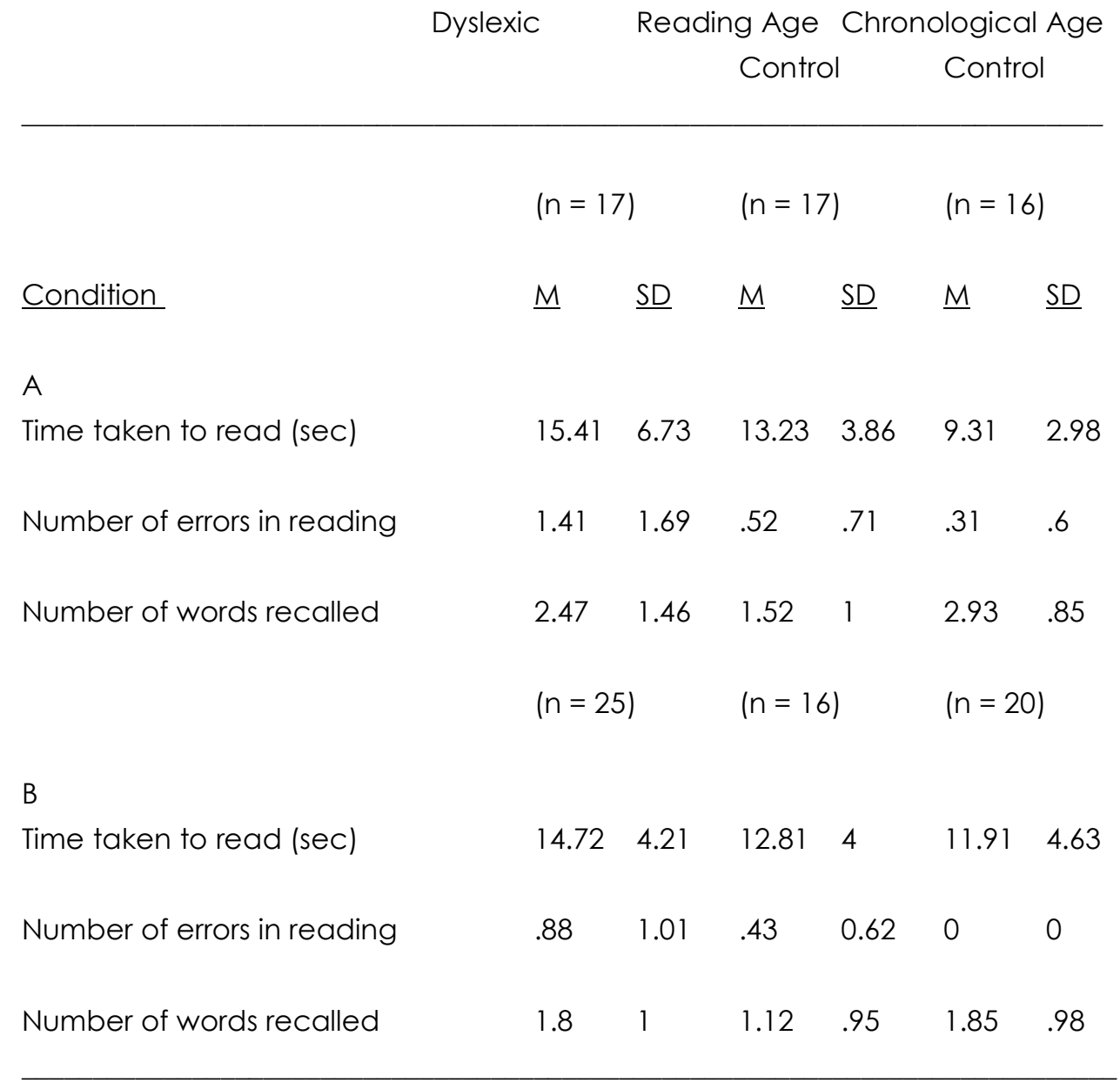

A 3 Group (dyslexic, RA, CA) by 2 Condition (A, B) factorial ANOVA was conducted separately on 2 of the main measures taken from the present study for the time to read words and for the number of words recalled. As the SD for errors in reading for the CA group was zero an independent group's t-test was conducted for only the dyslexic group and the RA control.

Time to read words - Analysis of the data on the time taken to read the list of words showed a significant main effect for Group with $F(2,105)=24.16$, MSE $=17.35, p<$ .0001 . Post-hoc comparisons of the means using Fisher's LSD showed significant differences between dyslexics and CA, $p<.0001$, SE $=.94$ ), (Cohen's $d=1.6$ ) and between dyslexics and RA, $p<.04, \mathrm{SE}=.96$ (Cohen's $d=.43$ ) and between RA and $\mathrm{CA}, \mathrm{p}<.0001, \mathrm{SE}=1$ (Cohen's $d=-1.4$ ). There was however, no significant main effects for condition with $F(1,105)=1.28, M S E=17.35, p<.2$ or an interaction $F(2$, $105)=1.97$, MSE $=17.35, p<.8$ 
Errors in reading words- Independent groups t-test showed that for condition A there was a significant difference between Dyslexics and RA matched on the number of errors made in naming words with dyslexics making more errors $\dagger(32)=1.97, p<.05$, $\mathrm{SE}=.4496$ (Cohen's $d=.43$ ). For condition B independent groups t-test showed no significant difference with $\dagger(39)=1.56, \mathrm{p}<.12, \mathrm{SE}=.28$.

Number of words recalled- Analysis of the data on the number of words correctly recalled showed a significant main effect for Group with $F(2,105)=9.41$, MSE $=1.12$, $p<.0001$. Post-hoc comparisons of the means using Fisher's LSD showed significant differences between dyslexics and RA, $p<.003$, SE $=.24$, (Cohen's $d=.67$ ) and between CA and RA, $p<.0001$, SE $=0.25$, (Cohen's $d=.97$ ) but not between dyslexics and CA $p<.27$, (SE = .24). There was also a significant main effect for condition with $F(1,105)=12.54$, MSE $=1.12, \mathrm{p}<.001$ but no significant interaction effect $F(2,105)=.91$, MSE $=1.12, p<.4$.

Table 2: Inter-correlations between the variables in the present study

\begin{tabular}{|cllll|}
\hline Measure & 1 & 2 & 3 & 4 \\
\hline Age & -- & -.17 & $.31^{*}$ & $-.25^{*}$ \\
\hline Number of Errors & & -- & -.12 & $.41^{*}$ \\
\hline Words Recalled & & -- & -.1 \\
\hline Time to Read Words & & & \\
\hline
\end{tabular}

${ }^{*} p<0.01$

Correlations between variables - As noted in table 2 overall older readers have significantly better recall and are faster in reading words.

\section{Discussion}

The first aim of the present study was to compare reading performance of developmental dyslexics in transparent Polish orthography with unimpaired RA and CA controls. The results showed that similar to studies on scripts with a mixture of opaque and transparent spellings such as Persian, dyslexics are significantly slower than the two unimpaired groups in the time taken to read words. This result suggests that reading in an entirely transparent script per se is not a significant factor affecting the magnitude of differences between dyslexics and the two unimpaired controls as compared to scripts with a more opaque relationship.

A second aim of the present study was to examine short-term recall of words by dyslexics, RA and CA controls. The results showed that developmental dyslexics have 
a superior memory compared to RA and comparable to CA group in both conditions of the experiment namely; with prior instructions to expect recall and with no prior instructions. This finding is in line with Baluch \& Danaye-Tousie's (2006a) and thus suggests a greater memory superiority for dyslexics compared to RA even when participants were not informed of a follow up recall of words. Furthermore, the analysis of correlations showed that there is no overall relationship between time to read words and recall, rather age of participants was found to be a significant factor both affecting time to read words and number of words recalled. In what follows each aspect of the above finding is further elaborated.

Reading Time and Errors

Generally it is expected that developmental dyslexics show poorer performance in word reading and number of errors compared with unimpaired readers (e.g., Snowling, 1980; Swan \& Goswami, 1997). However, previous research has also shown that the magnitude of differences may differ according to orthographic transparency (Goswami, Ziegler, Dalton, \& Schneider, 2001). The magnitude of differences in performance on phonological tasks between dyslexics and unimpaired readers for a shallow orthography like German or Greek was reported to be less than the difference between dyslexic and unimpaired readers for a deep orthography such as English (Goulandris, 2003). Olson, Wise, Conners, Rack, \& Fulker, (1989) reported that both in the time taken to read and number of errors made, dyslexic English readers could have a poorer performance compared to an RA group of readers. However, when Baluch and Danaye Tousie (2006a) compared naming performance for high frequency opaque and transparent words it was found that although dyslexics have greater difficulties in reading and make more errors with opaque spellings, there are nevertheless significant differences in performance between dyslexics and RA in reading transparent words. Thus the question was raised as to whether a similar result will be obtained in a entirely transparent writing system with regard to high frequency words?

In the present study Polish developmental dyslexics read slower than the RA group in both conditions of the study. Thus insofar as reading time is concerned it seems that even in a transparent orthography the time to read a word is significantly slower for dyslexics readers compared to RA control. Using the argument put forward by Castles and Coltheart (1993), Manis et al., (1996) if developmental dyslexics differ from unimpaired readers of the same reading age this may demonstrate the extent of deviance from patterns of reading which do not correspond to any of the normal reading stages. This finding has now been demonstrated not only with Persian words (Baluch \& Danaye-Tousie 2006a) and English (Olson et al., 1989) but also with 
transparent Polish. In line with the present finding is a recent chapter by Reid (2005) in which she has concluded that the prevalence of developmental dyslexia is as high as in languages with more opaque spelling sound correspondences and that reading rates and errors are significantly higher for Polish dyslexics than unimpaired controls.

However, important to note that when considering the number of errors made by Polish dyslexics in the present study it was noted that more errors were made under the condition that they were told to expect recall compared to when they there were no such instructions. It is possible to argue that his might be due to dyslexics deficits in relation to their attention system (e.g., Shallice \& Burgess 1993). The extra burden to expect recall of words at a later stage may have contributed to dyslexics' greater number of errors under condition $A$ of the experiment.

Number of Words Recalled

It has been argued that dyslexics' difficulty in phonological processing may be a factor affecting working memory (Baddeley, 1990; Just \& Carpenter, 1992). The reason could be at least two-fold: a) difficulties in encoding words due to poor grapheme-phoneme processes and b) difficulties due to the taxing of the limited capacity attention system due to generally slower processing strategy. A question pursued in the present study is whether memory performance of dyslexics is also affected by spelling transparency. Previously, Baluch and Danaye-Tousie (2006a) reported that contrary to word reading performance, dyslexics' recall of words, in particular transparent words, was comparable to CA control and significantly better than RA control. However, in the latter research participants were specifically instructed to expect recall of words at a later stage. It was thus not clear whether it was the impact of expecting recall of words that helped with greater memory performance of older dyslexic readers or a general superiority of short-term memory. The present findings showed that in the transparent Polish orthography developmental dyslexics have indeed a superior memory compared to that of RA control and their performance is comparable to CA group under both conditions of the experiment. This finding has some support in the literature. D' Angiulli, Siegel and Serra (2001) reported that although there are differences in phonological tasks between bilingual and monolingual English and Italian children as a function of level of skill and spelling transparency, the differences were minimal with regards to working memory. Furthermore, Ellis, McDougall and Monk (1996) reported that dyslexic reading comprehension was superior to that of the reading age controls and precocious readers and their listening comprehension was better than that of the other three groups. Considering that comprehension relies on efficient 
processing of working memory perhaps one may argue that the results of Ellis et al., (1996) are further support that dyslexics' memory performance shows no more deficit than a matched age group of unimpaired readers. However, bearing in mind that the present findings on Polish were based on recall of lists of mainly high frequency words, it may be concluded that insofar as high frequency category of words are concerned there is no difference in memory performance between developmental dyslexics and their age matched unimpaired controls. Perhaps this is because dyslexics are faster in visual processing (Ellis et al., 1996) and may use their orthographic knowledge to compensate for lack of efficient phonological processing.

Task demands

In the present study it was found that the inclusion of a condition in which participants specifically expect a memory recall did have a significant main effect on all participants' performance. There was however no group by condition interaction. The literature on task demands affecting dyslexic's performance is not entirely consistent. Shallice and Burgess (1993) argued that dyslexics had significantly greater problems than the control group when first encountered with a reading task because task demands are still novel for the participant. Nicolson and Fawcett (2000) on the other hand have argued that although dyslexic children are poorer at memory tasks this was not due to their misunderstanding of the instructions. A further possibility was raised by Rack et al., (1992) in which they argued that dyslexics may have superior memory compared to RA because such readers are two years older and more cognitively advanced in responding to task demands and may bring additional skills to the reading task in response to task demands. Hence, in a memory test dyslexics perform better than RA control due to their age advantage (Swanson, 1993). In the present study, whilst there were significant relationships between age and recall, there was no indication that one particular group benefited more than another group i.e. lack of significant interaction between participants and conditions. Thus there is no indication that dyslexic or older readers benefited more than younger ones because they took more advantage of prior instructions when reading the lists of words.

Implications of the results

The findings of the present study on Polish further reinforces a universal account (Goulandris, 2003) that developmental dyslexics are indeed slower than RA and CA unimpaired readers even in a very transparent orthography. However, regarding 
short term memory performance dyslexic readers are comparable to CA and superior to RA. This suggests that deficits in reading by dyslexics is more related to lower levels of information processing than higher level memory processes. Such findings have important implications for teaching and intervention strategies for developmental dyslexics in different orthographies.

\section{References}

Adams, M, J. (1990). Beginning to read: Thinking and learning about print. Cambridge, MA: MIT Press.

Baddeley, A. D. (1986). Working memory. Oxford: Clarendon Press.

Baddeley, A. D. (1990). Human memory: Theory and practice. Hillsdale, NJ: Lawrence, Erlbaum Associates.

Baddeley, A. D., \& Hitch, G. J. (1993). The recency effect: Implicit learning with explicit retrieval. Memory \& Cognition, 21, 146_155.

Baluch, B., \& Danaye-Tousie, M. (2006a). Spelling transparency and its impact on dyslexic and unimpaired children's memory for words. Annals of Dyslexia, 56 (2), 1-15.

Baluch, B. \& Danaye-Tousie, M. (2006b). Memory for words as a function of spelling transparency. The Journal of Psychology 140, 2, 95-105

Barron, R.W. (1986). Word recognition in early reading: A review of the direct and indirect access hypotheses. Cognition, 24, 93-119.

Bogdanowicz, M. (2006). Specificzne Trudności w Czytaniu I Pisaniu, [Specific Difficulties in Reading and Writing] . In G. Krasowicz-Kupis (Eds.) Dysleksja Rozwojowa. Gdańsk: Wydawnictwo Harmonia [Developmental Dyslexia]

Brady, S., \& Shankweiler, D. (1991). Phonological processes in literacy. Hillsdale, NJ: Laurence Erlbaum Associates.

Brzezińska, A., \& Ziółkowska, M. (1987). Doskonalenie umiejętności czytania uczniów klasy II, [ Accomplishing reading abilities in grade II pupils]. In A.Brzezińska (Eds) Czytanie i pisanie-nowy język dziecka [Reading and writing- a child's new language]. Warsaw: WsiP. 
Castles, A., \& Coltheart, M. (1993). Varieties of developmental dyslexia. Cognition, 47, $149-180$.

Coltheart, M. (1978). Lexical access in simple reading tasks. In G. Underwood (Ed.) Strategies of information processing (pp. 151-216). San Diego, CA: Academic Press.

Coltheart, M., Curtis, B. Atkins, P. and Haller, M. (1993). Models of reading aloud: Dualroute and parallel-distributed-processing approaches. Psychological Review, 100, 589608.

Cossu, G., Gugliotta, M., \& Marshall, J.C. (1995). Acquisition of reading and written spelling in a transparent orthography: Two non-parallel processes? Reading and Writing, 7, 9-22.

D'Angiulli, A., Siegel, L.S., \& Serra, E. (2001). The development of Redding in English and Italian in bilingual children. Applied Psycholinguistics, 22, 479-507.

De Gelder, B., \& Vroomen, J. (1991). Phonological deficits: Beneath the surface of reading acquisition. Psychological Research, 53, 88-97.

de Jong, P. F. (1998). Working memory deficits of reading disabled children. Journal of Experimental Child Psychology, 70, 75-96.

Ellis, A.W., McDougall, S.J.P. and Monk, A.F. (1996) Are dyslexics different? 1. A comparison between dyslexics, reading age controls, poor readers and precocious readers, Dyslexia, 2, 31-58.

Ehri, L. (1999). Phases of development in learning to read words. In J. Oakhill \& R. Beard (Eds.), Reading Development and the Teaching of Reading: A Psychological Perspective, 79-108. Oxford, UK: Blackwell Publishers.

Ehri, L. \& Snowling, M. (2004) Developmental variation in word recognition. In B. Shulman, K. Apel, B. Ehren, E. Silliman, \& C. Stone (Eds.), Handbook of Language and Literacy Development and Disorders. New York: Guilford

Frith, U. (Ed.) (1980). Cognitive Processes in Spelling, London: Academic Press Frith, U., Wimmer, H., \& Landerl, K. (1998). Differences in phonological recoding in German- and English-speaking children. Scientific Studies of Reading , 2, 31-54. 
Frost, R., Katz, L., \& Bentin, S. (1987). Strategies for visual word recognition and orthographic depth: A multilingual comparison. Journal of Experimental Psychology: Human Perception and Performance, 13, 104-115.

Funnell, E. \& Davison, M. (1989). Lexical capture: A developmental disorder of reading and spelling. The Quarterly Journal of Experimental Psychology Section A, 41,(3)_, 471 487

Geva, E., \& Siegel, L. (2000). Orthographic and cognitive factors in the concurrent development of basic reading skills in two languages. Reading and Writing, 12, 1-30.

Goswami, U., \& Bryant, P. (1990). Phonological skills and learning to read. Hove, East Sussex: Lawrence Erlbaum.

Goswami, U., Ziegler, J. C., Dalton, L., \& Schneider, W. (2001). Pseudohomophone effects and phonological recoding procedures in reading development in English and German. Journal of Memory and Language, 45, 648-664.

Goulandris, N. (2003). Dyslexia in different languages: Cross-linguistic comparisons. London: Whurr Publishers.

Gupta, A. (2004). Reading difficulties of Hindi-Speaking children with developmental dyslexia. Reading and Writing 17, 79-99

Jackson, N.E., \& Coltheart, M. (2001). Routes to reading success and failure: Toward an integrated cognitive psychology of atypical reading. New York: Taylor \& Francis.

Just, M. A., \& Carpenter, P. A. (1992). A capacity theory of comprehension: Individual differences in working memory. Psychological Review, 99, 122-149.

Manis, F. R., Seidenberg, M. S., Doi, L. M., McBride-Chang, C., \& Peterson, A. (1996). On the bases of two subtypes of developmental dyslexia. Cognition, 58, 157-195.

McDougall, S. J. P., \& Donohoe, R. (2002). Reading ability and memory span: Long term memory contribution to span for good and poor readers. Reading and Writing, 15, 359_387.

Messbaver, V. C. S., \& de Jong, P, F. (2004). Verbal and non-verbal paired associate learning in Dutch dyslexic children. Paper presented to the $5^{\text {th }}$ BDA international conference York, England. 
Nicolson, R. I., \& Fawcett, A. J. (2000). Long-term learning in dyslexic children. European Journal of Cognitive Psychology, 12 (3), 357_393.

Nikolopoulos, D., \& Goulandris, N. (2000). The cognitive determinants of literacy skills in a regular orthography. In M. Perkines, \& S. Howard (Eds), New directions in language development and disorders (pp. 261-270). New York: Plenum Publishers.

Olson, R. K., Wise, B., Conners, F., Rack, J., \& Fulker, D. (1989). Specific deficits in component reading and language skills: Genetic and environmental influences. Journal of Learning Disabilities, 22, 339-348.

Oney, B., Peter, M., \& Katz, L. (1997). Phonological Processing in Printed Word Recognition: Effects of Age and Writing System. Scientific Studies of Reading, 1, 65-83.

Porpodas, C.D., Pantelis, S. N., \& Hantziou, E. (1990). Phonological and lexical encoding processes in beginning readers: Effects of age and word characteristics. Reading and Writing, 2, 197-208.

Rack, J.P., Hulme, C. Snowling, M.J. \& Wightman, J. (1994) The role of phonology in young children's learning of sight words: the direct mapping hypothesis. Journal of Experimental Child Psychology, 57, 42-71.

Rack, J. P., Snowling, M. J., \& Olson, R. K. (1992). The nonword reading deficit in developmental dyslexia: A review. Reading Research Quarterly, 27, 1, 28-53.

Raman, I. Baluch. B., \& Sneddon, P (1996). What is the cognitive system's preferred route for deriving phonology from print. European Psychologist, 1, (3), 221-227 Raven, J.C., Court, J.H., \& Raven, J. (1977). Raven's Coloured Progressive Matrices. London: H.K. Lewis \& Co. Ltd.

Reid, A. (2005). Developmental Dyslexia: Evidence from Polish. In R. Malatesha \& Joshi, P.G. Aaron (Eds), Handbook of orthographies and literacy (pp. 249-274).

Shallice, T., \& Burgess, P. W. (1993). Supervisory control of action and thought selection. In A. Baddeley \& L. Weiskrantz (Eds.), Attention: Selection, awareness, and control. A tribute to Donald Broadbent (pp. 171-187). Oxford, UK: Oxford University Press.

Smith- Spark , J. H., \& Fisk, J. E. (2007). Working memory functioning in developmental dyslexia. Memory, 15 (1), 34-56 
Snowling, M. J. (1980). The development of grapheme-phoneme correspondence in normal and dyslexic readers. Journal of Experimental Child Psychology, 29, 294- 305.

Snowling, M. J. (2004). Language skills and learning to read. The Psychologist, 17, 438-41.

Sprenger-Charolles, L., Siegel, L. S., Bechennec, D. \& Serniclaes, W. (2003). Development of phonological and orthographic processing in reading aloud, in silent reading, and in spelling: A four-year longitudinal study Journal of $\backslash$ Experimental Child Psychology 84 (3), 194-217.

Swan, D., \& Goswami, U. (1997). Picture naming deficits in developmental dyslexia: The phonological representations hypothesis. Brain \& Language, 56, 334-53.

Swanson, H. L. (1993). Working memory in learning disability subgroups. Journal of Experimental Child Psychology, 56, 87-114.

Wagner, R. K., \& Torgesen, J. K. (1987). The nature of phonological processing and its causal role in the acquisition of reading skills. Psychological Bulletin, 101, 192-212.

About the authors:

Natasza Dominika Nalesnik, BSc is currently a Postgraduate student in Mental Health at the Institute of Psychiatry, University of London. She is a native speaker of Polish and has experience of teaching in Polish schools.

Email: natasza_n@yahoo.co.uk

Bahman Baluch, MA, PhD, CPsychol, AFBPsS, CSci

Reader in Experimental Psychology and author of over 60 refereed publications, conference presentations and book chapters. His research interests include cognitive processes of reading, psychological aspects of infertility and organ donation.

School of Health and Social Sciences

Middlesex University

The Burroughs

London NW4 4BT

Tel: +44 (0)20 84115375

Email: Bahman1@mdx.ac.uk 


\section{Appendix}

Experimental Words in their Polish Spelling and Meaning

Polish spelling

frak

wstyd

krzyk

stok

las

łłuszcz

wódz

rytm

trop

wzór

grzyb

wąż
Meaning

tail-coat

shame

scream

slope

wood

grease

leader

rhythm

trace

pattern

mushroom

snake 